\title{
La agenda de desarrollo sostenible después del 2015 de acuerdo a las
}

Naciones Unidas y el Perú

En el presente artículo, la autora analiza el alcance de las recomendaciones de la ONU en materia de desarrollo sostenible. La autora indica que es posible lograr la mejoría económica e institucional de las naciones a partir de políticas ambientales sostenibles. Para tal efecto, introduce el caso de las cuencas de los ríos Pastaza, Corrientes, Tigre y Marañón en Loreto, área de influencia del Lote $1 A B$, el cual genera aproximadamente el $20 \%$ de la producción nacional de petróleo.

Abogada por la Universidad de Lima. Máster en Organización J urídica Económica y Social del Medio Ambiente por la Escuela de Organización Industrial (EOI). Socia y Responsable del Área Ambiental del Estudio Ferrero Abogados. 


\section{La agenda de desarrollo sostenible después del 2015, de acuerdo a las Naciones Unidas, y el Penú}

El Secretario General de las Naciones Unidas presentó en diciembre del 2014 el informe de la agenda de desarrollo sostenible después del 2015 al que denominó “El camino hacia la dignidad para el 2030: acabar con la pobreza y transformar vidas protegiendo el planeta".

Es relevante hacer un pequeño resumen de dicho informe para tomar conciencia del reto que está planteando al mundo una institución como las Naciones Unidas, respecto a su visión de desarrollo sostenible para los próximos 15 años para, con ello, posteriormente exponer un caso concreto peruano que pueda reflejar el nivel de avance en que se encuentra el país en ese tema.

\section{Informe de las Naciones Unidas}

En dicho informe se establecen seis elementos esenciales para fortalecer la agenda de desarrollo sostenible:

a) Dignidad: Acabar con la pobreza y luchar contra las desigualdades.

b) Personas: Garantizar una vida sana, el conocimiento y la inclusión de las mujeres y los niños.

c) Prosperidad: Desarrollar una economía sólida, inclusiva y transformadora.

d) Planeta: Proteger nuestros ecosistemas para todas las sociedades y para nuestros hijos.

e) Justicia: Promover sociedades seguras y pacíficas e instituciones sólidas.

f) Asociación: Catalizar la solidaridad mundial para el desarrollo sostenible.

Asimismo, el informe señala que para ejecutar la agenda se necesita: financiación, tecnología e inversiones en capacidades de desarrollo sostenible para asegurar que los compromisos se transformen en acciones.

Sobre los elementos esenciales establece lo siguiente:

a) Dignidad: Acabar con la pobreza y luchar contra las desigualdades.

La erradicación de la pobreza para el año 2030 es el objetivo primordial de la agenda de desarrollo sostenible. Como se indica, se debe reducir la brecha que existe entre nuestra determinación de garantizar una vida digna para todos y la realidad de la pobreza persistente y la intensificación de la desigualdad. 
La agenda de desarrollo sostenible después

del 2015 de acuerdo a la Naciones Unidas y

el Perú

b) Personas: Garantizar una vida sana, el conocimiento y la inclusión de las mujeres y los niños.

Se debe garantizar que se aplique una política de tolerancia cero respecto de la violencia contra las mujeres y las niñas y su explotación. Así como una cobertura, acceso y asequibilidad de la atención universal de la salud.

c) Prosperidad: Desarrollar una economía sólida, inclusiva y transformadora.

El crecimiento económico debería conducir a una prosperidad compartida. La solidez de una economía debe medirse por el grado en que atiende las necesidades de la población y teniendo en cuenta hasta qué punto lo hace de manera sostenible y equitativa. Inclusivo, medido no solo considerando el PBI sino también el bienestar humano, la sostenibilidad y la equidad.

d) Planeta: Proteger nuestros ecosistemas para todas las sociedades y para nuestros hijos.

Se debe hacer frente de forma equitativa al cambio climático, poner freno a la pérdida de diversidad biológica y abordar las cuestiones de la desertificación y el uso insostenible de la tierra. Así como la gestión sostenible de los recursos hídricos y de los desechos y los productos químicos, promover las fuentes de energía renovables y más eficientes; desvincular el crecimiento económico de la degradación ambiental, entre otros.

e) Justicia: Promover sociedades seguras y pacíficas e instituciones sólidas.

Una gobernanza eficaz para el desarrollo sostenible exige que las instituciones públicas de todos los países y a todos los niveles sean inclusivas, participativas y rindan cuentas ante la población.

f) Asociación: Catalizar la solidaridad mundial para el desarrollo sostenible.

La movilización de apoyo exigirá voluntad política y acción en todos los frentes, nacional e internacional, público y privado a través de la ayuda y el comercio, la reglamentación, la tributación y la inversión. Se debe armonizar la acción privada y las políticas públicas. Todo esto significa el establecimiento de asociaciones entre el sector público, el sector privado y la población, responsables y basadas en principios.

Además, este informe indica que el desarrollo sostenible debe ser una agenda integrada para soluciones económicas, ambientales y sociales. Esta integración constituye la base de modelos económicos que benefician a las personas y el medio 
ambiente de soluciones ambientales que contribuyen a los progresos; de enfoques sociales que se suman al dinamismo económico con el medio ambiente; y del fortalecimiento de los derechos humanos, la igualdad y la sostenibilidad.

Por último, el informe establece que el objetivo es la transformación. Debemos transformar nuestras economías, el medio ambiente y nuestras sociedades. Debemos cambiar nuestra forma de pensar, nuestra conducta y nuestros hábitos destructivos. Debemos apoyar la integración de ciertos elementos esenciales: la dignidad, las personas, la prosperidad, el planeta, la justicia y las alianzas. Este futuro solo será posible si logramos movilizar colectivamente la voluntad política y los recursos necesarios.

\section{Reto para el país}

Como se puede apreciar, los seis elementos propuestos por las Naciones Unidas constituyen un reto muy ambicioso para cualquier país, y el nuestro no es la excepción. El país viene desde hace unos años haciendo algunos avances, de la forma en que cada gobierno lo crea más conveniente, en disminuir los índices de pobreza; en la lucha contra la violencia contra la mujer y la atención universal de la salud; y en la lucha contra la pérdida de diversidad biológica, entre otros. Sin embargo, estamos muy lejos de acabar con la pobreza, de lograr la igualdad entre los géneros y de ingresos; en considerar como crecimiento no solo el incremento del PBI sino también el bienestar humano, la sostenibilidad y la equidad; o salvaguardar los bosques, proteger la flora y la fauna o la gestión sostenible del agua, así como vivir libres de la violencia, crisis y conflictos.

Como ejemplo de lo lejos que estamos de lograr el reto planteado por las Naciones Unidas, y para que ustedes tomen conciencia de nuestra realidad y saquen sus propias conclusiones sobre el nivel de avance del país en los elementos esenciales para el desarrollo sostenible, a continuación voy a exponer mi experiencia en un caso de conflicto socioambiental emblemático.

\section{Mejoramiento de las condiciones sociales y ambientales de las poblaciones de las cuencas de los ríos Pastaza, Tigre, Corrientes y Marañón, del departamento de Loreto}

El contrato del actual operador del lote $1 A B$ (futuro lote 192) vence en agosto del 2015, por lo que el Estado debía de atender las cinco condiciones mínimas requeridas por las cuatro federaciones ${ }^{1}$ que representan a las comunidades nativas de las cuencas

Federación Indígena Quechua del Pastaza (FEDIQUEP); Federación de Comunidades Nativas del Corriente (FECONACO); Federación de Comunidades Nativas del Tigre (FECONAT); y la Asociación Cocama de Desarrollo y Conservación San Pablo de Tipishca (ACODECOSPAT). 
La agenda de desarrollo sostenible después del 2015 de acuerdo a la Naciones Unidas y el Perú

de los ríos Pastaza, Tigre, Corrientes y Marañón, área de influencia del lote, antes de dar inicio a los procesos de consulta previa y la licitación internacional para otorgar la buena pro al nuevo operador del lote.

Todo este proceso se llevó a cabo en un clima de conflicto social entre ciertas comunidades nativas de la zona y el actual operador del lote por supuestos incumplimientos de compromisos y contaminación ambiental.

El proceso de diálogo se inició hace más de 2 años con la creación de una Comisión Multisectorial $^{2}$ encargada de analizar, diseñar y proponer medidas que permitan mejorar las condiciones sociales y ambientales de la población en las cuencas de los ríos Pastaza, Tigre, Corrientes y Marañón del departamento de Loreto. En el seno de la Comisión Multisectorial se debía de tratar de encontrar la forma de atender las cinco condiciones mínimas antes indicadas.

El lote $1 A B$ genera aproximadamente el $20 \%$ del petróleo nacional y se encuentra en explotación desde hace más de 40 años. Sin embargo, la desatención a la población ubicada dentro del lote y en su área de influencia siempre ha sido alarmante. Así tenemos que el Estado determinó que en las cuatro cuencas existían niveles de riesgo significativo para la vida, la salud de la población y al ambiente, considerándose como un nivel de daño ambiental significativo ${ }^{3}$. También se evidenció que no existían sistemas de abastecimiento de agua apta para el consumo humano en diversas localidades dentro del ámbito territorial o que, contando con dichos sistemas, no estaban funcionando adecuadamente; que los pobladores de dichas cuencas venían consumiendo agua que muestra valores que no cumplen los límites máximos permisibles para el consumo humano y que todo ello, se convirtió en un problema

2 Resolución Suprema 200-2012-PCM del 28 de junio de 2012. Posteriormente, con Resolución Suprema 212-2013-PCM, se prorrogó su plazo de vigencia hasta el 13 de julio de 2014. Además, posteriormente, mediante Resolución Suprema 119-2014-PCM se conforma la Comisión Multisectorial de carácter temporal denominada "Desarrollo de las Cuencas del Pastaza, Tigre, Corrientes y Marañón, del departamento de Loreto".

3 Resolución Ministerial 136-2014-MINAM, Declaran en Emergencia Ambiental la parte baja de la cuenca del rio Marañón. Resolución Ministerial 370-2013-MINAM, Declaran en Emergencia Ambiental la parte alta de la cuenca del rio Tigre. Resolución Ministerial 2632013-MINAM, Declaran en Emergencia Ambiental la cuenca del rio Corrientes. Resolución Ministerial 094-2013-MINAM, Declaran en Emergencia Ambiental la cuenca del rio Pastaza. 
sanitario debido a la ocurrencia de enfermedades diarreicas agudas y por ende, un riesgo elevado para la salud y la vida ${ }^{4}$.

Además, de todo ello, también habían problemas de contaminación ambiental de agua y suelos, deficiente educación, carencia de electrificación rural, inexistencia de proyectos productivos, falta de pago por el uso de las tierras, entre otros.

Como respuesta a esta desatención por parte del Estado, las federaciones plantearon la atención de las siguientes condiciones mínimas para dar su conformidad a los procesos de consulta previa y de licitación del lote 192. Las cinco condiciones mínimas fueron: i) titulación, ii) diagnóstico social y ambiental, iii) saneamiento básico, iv) remediación ambiental, v) compensación por uso de territorios e indemnización por daños.

Como resultado del proceso de diálogo, el Estado ha asumido compromisos por más de 100 millones de soles en temas de saneamiento ambiental, desarrollo integral intercultural, remediación ambiental y titulación de tierras ${ }^{5}$. El monto podría incrementarse especialmente en lo que se refiere a la remediación ambiental.

Estos compromisos beneficiarán a más de 100,000 pobladores de las cuatro cuencas y es considerado un hecho histórico por las partes debido a que se atenderían necesidades requeridas desde hace muchos años en una zona donde se viene desarrollando actividad petrolera desde hace más de 40 años. Con estos compromisos se busca reducir la brecha de desigualdad y mejorar la calidad de vida de la población.

El valor de este acuerdo es que soluciona uno de los principales conflictos sociales del país, se da inicio al proceso de licitación y al proceso de consulta previa para un lote que genera el $20 \%$ del petróleo nacional y se atiende las demandas socio-ambientales de cerca de 6,600 pobladores, afectados de una u otra manera por la explotación petrolera realizada desde 1971.

Por años estas comunidades nativas se encuentran en la pobreza y desigualdad; la atención de la salud ha sido deficiente a pesar de los estudios que concluyeron que las personas estaban intoxicadas; sin proyectos que les permitan mejorar el bienestar de su población; con problemas constantes de contaminación por la actividad petrolera;

4 Decreto Supremo 006-2014-SA, Declaran Emergencia Sanitaria en localidades de las cuencas de los ríos Pastaza, Corrientes. Tigre y Marañón, pertenecientes al departamento de Loreto.

5 El acta fue suscrita el 10 de marzo del presente año con la presencia de tres de los cuatro presidentes de las federaciones y por parte del Estado, la Primera Ministra, Ana Jara; los Ministros de Vivienda, Construcción y Saneamiento, Milton Von Hesse; de Ambiente, Manuel Pulgar Vidal; de Educación, Jaime Saavedra; de Cultura, Diana Álvarez Calderón; de Desarrollo e Inclusión Social, Paola Bustamante; y de Energía y Minas, Rosa María Ortiz. 
La agenda de desarrollo sostenible después

del 2015 de acuerdo a la Naciones Unidas y

el Perú

äFFRSETI

sin haber sido tomados en cuenta por las instituciones públicas; $y$, sin voluntad política para cambiar esta situación.

Por ello, tomando como ejemplo este caso, se considera que el país se encuentra muy lejos de lograr los seis elementos planteados por las Naciones Unidas para la agenda de desarrollo sostenible. Sin embargo, este acuerdo podría ser el punto de partida para ese proceso, si es que esa misma voluntad política se institucionaliza y se replica a nivel nacional.

Sin embargo, también es conveniente resaltar que se considera que este acuerdo no se hubiera podido lograr sin la voluntad política de un sector del ejecutivo, sin la presión que tenía el Estado para obtener resultados debido a que el contrato del actual operador vence en agosto del presente año y sin la voluntad de los presidentes de las cuatro federaciones de entender las limitaciones del gobierno y de flexibilizar posiciones.

Ya usted, querido lector, sacará sus propias conclusiones del nivel de avance integral del Estado peruano en el camino a cumplir los seis elementos esenciales planteados por las Naciones Unidas y si las respuestas concretas dadas a la población, en el caso concreto de las cuencas de los ríos Pastaza, Corrientes, Tigre y Marañón, son reactivas a una coyuntura determinada o el primer paso de un largo proceso hacia el desarrollo sostenible. 